\title{
The problem with being choosy when it comes to sperm selection
}

\author{
David F. Albertini ${ }^{1}$
}

Published online: 11 July 2019

(C) Springer Science+Business Media, LLC, part of Springer Nature 2019

Before the introduction of ICSI, preparation of semen for insemination by IVF was a relatively straightforward matter. Fresh ejaculates were rendered in simple ways such that motility, concentration, and morphology met the then accepted criteria to move forward with coincubation with intact cumulus-oocyte-complexes (COC). Embryo production was to a certain extent "gentler and kinder" from the egg-sperm interaction perspective, and fertilization checks amounted to determining what fraction of the COCs were on their way once two pronuclei were verified and any triploids were discarded as a result of dispermic penetration.

But not all oocytes fertilized, and in all too many cases, cycles were terminated because of fertilization failure. Alternative strategies were non-existent in the years prior to cryopreservation. And once ICSI appeared, a whole new paradigm emerged. At that point, the need arose to really figure out which sperm were the best candidates for ICSI-an expectation that has grown with time as ICSI has become the default route to embryo production in human ART centers around the world, even sans male factor indications.

Although Mother Nature has long successfully deployed her own sperm selection strategies for organisms that rely upon internal fertilization to propagate their species, our efforts at de-identifying all the losers relative to the embarrassment of riches resident within semen from healthy men have been woefully incomplete. And knowing full well the shortcomings of extrapolating from total semen analysis to those special few that will get the call from the bullpen (sorry for the baseball metaphor), we have been left with no other choice but to find biomarkers of a level of prevalence in washed sperm that could provide a rational basis for sperm selection we intuit would be best for making an embryo. Maybe!

Despite mounting evidence for a repertoire of molecular devices materially expanding what is now understood to be "Dad's" legacy to the zygote (move over genomes and

David F. Albertini

eicjarg@gmail.com

1 Center for Human Reproduction, New York, NY, USA centrosomes), sperm quality assessment as we know it today has become a feast for purveyors of fragmented DNA. This comes as no surprise given our collective obsession with the importance of DNA in traditional genetics when attempting to select for properties in oocytes, sperm, or embryos that might be carrying something amiss in genomes which could lead to gestational failure or negatively affect offspring!

Don Evenson got the ball rolling once the importance of chromatin packaging for normal fertilization was realized in the early studies on mammalian sperm [1]. And it did not take too long for reproductive biologists to demonstrate that concerns were warranted beyond the abilities of an oocyte to unravel the complex chromatin packaging in sperm when DNA integrity was found to be associated with a number of characteristics of semen [2]. Some of the landmark studies provided a foundation for what we are now preoccupied with brought the complex topography of sperm chromatin, and the role of protamines, into focus elaborating upon the uniqueness of this form of DNA relative to that of somatic cells [3].

The pieces of this puzzle were gradually assembled into a plausible framework that has withstood the test of time, with the evolution of human ARTs generally and in the treatment of male infertility in particular. What emerged was a deeper understanding of the vulnerabilities that the male germ cell genome is subjected to during both spermatogenesis in the testis and along the pathway to fertilization [4]. And as if that was not enough, we now recognize that the repair of DNA damage incurred along this journey may rely upon devices that are deposited in the cytoplasm of the oocyte as a last-ditch effort to assure that the zygote inherits healthy DNA from both parents [5].

With this backdrop, this month we bring our readership a series of papers aimed at detailing further properties of sperm quality extending beyond the realm of genomes. The challenge here is to keep the broadening perspective on sperm quality in sight as attempts to equate or associate IVF or ICSI outcomes with characteristics of semen contribute to our expanding knowledge base. Comizzoli comments on several of these contributions to JARG, ranging from novel 
features of sperm plasma membrane lipid composition and function to what our treatment strategies themselves may be contributing to an already sensitive microenvironment within which the genome resides (Superficial and profound considerations about sperm quality; https://doi.org/10.1007/s10815019-01506).

While we continue to grasp for meaningful biomarkers of sperm quality and the relationship that future assays and indicators might have with more global aspects of semen quality, there is a note of optimism in the air as technology advances the limits of what we can learn from viable sperm preparations conforming with and extending beyond current practices. One such model approach has recently appeared in the literature where Raman spectroscopy has been brought to bear on the status of sperm head DNA [6]. As refinements in technology like this add to our understanding about the inner workings of sperm, in parallel, efforts should aim more directly at the iatrogenic manipulations of semen used to prepare samples for ICSI. Deviating too far away from the Mother Nature approach, and taking sperm fully out of physiological contexts (such as occurs during TESE), commands attention both for purposes of diagnosing male factor and also for its clinical management.

We close this month noting ongoing efforts using microfluidic devices to move away from traditional semen washing protocols to exploit what may be a complete picture of the levels of heterogeneity within a sperm population (Use of microfluidic sperm extraction chips as an alternative method in patients with recurrent in vitro fertilization failure; https://doi.org/10.1007/s10815-019-01480). While refreshing to see back-to-nature approaches like this, the spectrum of add-ons that have found their way into the clinic without having scrutinized fundamental biological principles must be avoided at all costs.

\section{References}

1. Evenson DP, Darzynkiewicz Z, Melamed MR. Relation of mammalian sperm chromatin heterogeneity to fertility. Science. 1980;210(4474):1131-3.

2. Irvine DS, Twigg JP, Gordon EL, Fulton N, Milne PA, Aitken RJ. DNA integrity in human spermatozoa: relationships with semen quality. J Androl. 2000;21(1):33-44.

3. Ward WS, Coffey DS. DNA packaging and organization in mammalian spermatozoa: comparison with somatic cells. Biol Reprod. 1991;44(4):569-74.

4. Barratt CL, Aitken RJ, Bjorndahl L, Carrell DT, de Boer P, Kvist U, et al. Sperm DNA: organization, protection and vulnerability: from basic science to clinical applications-a position report. Hum Reprod. 2010;25(4):824-38.

5. Menezo Y, Dale B, Cohen M. DNA damage and repair in human oocytes and embryos: a review. Zygote. 2010;18(4):357-65.

6. Da Costa R, Amaral S, Redmann K, Kliesch S, Schlatt S. Spectral features of nuclear DNA in human sperm assessed by Raman microspectroscopy: effects of UV-irradiation and hydration. PLoS One. 2018;13(11):e0207786.

Publisher's note Springer Nature remains neutral with regard to jurisdictional claims in published maps and institutional affiliations. 